\title{
Increased Loading Rates During Gait Correlate with Morphology of Unaffected Hip in Juveniles with Treated Developmental Hip Dysplasia
}

\author{
Wei-Chun Lee \\ National Taiwan University \\ Tsan-Yang Chen \\ National Taiwan University \\ Li-Wei Hung \\ National Taiwan University \\ Ting-Ming Wang \\ School of Medicine, National Taiwan University \\ Chia-Hsieh Chang \\ Chang Gung Memorial Hospital \\ Tung-Wu Lu ( $\nabla$ twlu@ntu.edu.tw ) \\ National Taiwan University
}

\section{Research Article}

Keywords: developmental dysplasia of the hip (DDH), increased loading rates, unaffected hip, gait analysis

Posted Date: February 24th, 2021

DOI: https://doi.org/10.21203/rs.3.rs-233488/v1

License: (c) (i) This work is licensed under a Creative Commons Attribution 4.0 International License. Read Full License 


\section{Abstract}

Long-term follow-up studies on children with surgically treated developmental dysplasia of the hip (DDH) have shown that not only the affected side progresses to premature osteoarthritis, but the unaffected side may also suffer from insidious hip dysplasia or osteonecrosis. The current gait analysis study identified the loading and unloading rates of the ground reaction forces (GRF) and lower limb joint axial forces during gait, and their correlations with the hip morphology in twenty juvenile patients with surgically treated unilateral DDH during toddlerhood. Radiographic measurements of the hips were taken, and the correlations between the morphological parameters and the loading and unloading rates were obtained. The patients showed greater-than-normal peak loading rates of the joint axial forces, and the loading rates on both the affected and unaffected sides were highly correlated to the acetabular index on the unaffected side, which was also significantly correlated with the peak unloading rates on the affected side. These results suggest that apart from regular follow-up of the affected hip, routine assessment of the morphological changes and/or increased loading rates of the unaffected hip is also important for early identification of any signs of insidious hip dysplasia and risk of premature degeneration of the cartilage.

\section{Introduction}

Developmental dysplasia of the hip (DDH) is the most common paediatric hip disorder needing surgical intervention ${ }^{1}$. Early diagnosis before six months of age and early treatment with a harness is the gold standard management for this disease ${ }^{2}$. In case of late diagnosis or failure to manage with a harness, closed or open reduction with or without pelvic osteotomy would be needed to correct the abnormal morphology of the hip ${ }^{3 ;}{ }^{4}$. Generally, even if hip dislocation was treated successfully by surgery either by closed or open reduction, there are usually remaining problems such as osteonecrosis in the femur, residual acetabular dysplasia, or residual subluxation of the hip ${ }^{5}$. Previous long-term follow-up studies on children treated for DDH with surgical reduction showed that not only the affected side would progress to premature osteoarthritis (OA), but that the unaffected side would also suffer from insidious hip dysplasia or osteonecrosis. ${ }^{6 ; 7}$ These problems are often a result of the residual hip morphological changes, and of the magnitudes and loading rates of the forces transmitted at the joint even after surgery. However, clinical follow-up has focused mainly on morphological changes of the hip joint using plain-film X-ray imaging. Monitoring the changes in both the hip morphology and loading conditions may provide more complete information for early detection of signs of increased risk of premature OA in patients treated for $\mathrm{DDH}$.

Higher loading rates at the tissue level generate more surface fissuring of cartilage than lower loading rates ${ }^{8}$. Surface fissures can propagate if the joint surface is subjected to rigorous repetitive loading, leading to $\mathrm{OA}^{9}$. For the joints of the lower extremities, repetitive loadings at high loading rates occur mainly at heel strike during gait. Precise end-point control of the lower limb during the swing phase is critical for a smooth heel contact at heel strike to reduce the ground reaction force (GRF) loading rates. Compromised swing limb control may lead to increased loading rates of the GRF, and thus those at the lower limb joints. Gait analysis has been widely used for quantifying the motion and loadings of the lower limb joints in various patient populations ${ }^{10-14}$. It allows not only a detailed examination of the diseased joint, but also of the compensatory changes of adjacent joints and joints of the contralateral limb ${ }^{13 ; 14}$. Using gait analysis, an increased loading rate was noted on both the affected and unaffected side in adolescents who had been treated for unilateral DDH by Pemberton's osteotomy during toddlerhood ${ }^{15}$. Long-term monitoring of the loading rates of the GRF and joint forces in these patients was suggested for early detection of any risk of premature $\mathrm{OA}^{15}$. However, no study has examined whether the increased bilateral loading rates during walking would be related to the morphology of the hips in juveniles after DDH surgery.

The purpose of the current study was to identify the loading and unloading rates of the GRF and joint axial forces in the lower limbs during gait and their possible correlations with the bilateral hip morphology in juveniles who had been treated 
for DDH during toddlerhood. It was hypothesized that loading rates of the GRF and joint axial forces in the affected limb would be correlated with the morphology of the affected hip.

\section{Materials And Methods}

All experiments of the current study were conducted under the approval of Chang Gung Memorial Hospital Institutional Review Board (IRB No. 201601982B0C501). All the experiments and procedures conformed to the Ethical Principles for Medical Research Involving Human Subjects (World Medical Association Declaration of Helsinki). Twenty patients (DDH group; 20 females; age: $7.1 \pm 1.9$ years; height: $119.7 \pm 13.7 \mathrm{~cm}$; mass: $22.5 \pm 5.5 \mathrm{~kg}$; leg length discrepancy: $0.5 \pm 0.3 \mathrm{~cm}$ ) who had been treated for unilateral developmental dislocation of the hip by reduction surgery at an age of $2.5 \pm 1.7$ years participated in the current study (Table 1). Written informed consents were obtained from the participants and their parents or guardians as approved by the Institutional Review Board. Of the 20 subjects in the DDH group, two had been treated with closed reduction, two with open reduction, and 16 had been treated by open reduction with Pemberton's osteotomy according to the severity. All subjects were able to walk without support, and were free of pain and infection of the hip or any other neuromuscular diseases that might influence ambulation. Follow-up radiographs showed that frontal-plane acetabular coverage was within normal range at the time of the gait experiment in all the subjects. For each subject, the neck-shaft angle (NSA), acetabular index (Al), femoral offset, center-edge angle (CEA), acetabular depth ratio, articulotrochanteric distance (ATD), c/b ratio, and Alsberg angle (AA) were measured from anteroposterior X-ray images of the pelvis for both sides at the time of the gait experiment (Fig. 1 and Table 1). Participants were excluded from the study if they had other neuromusculoskeletal diseases or neurological pathology that might affect gait. Thirteen healthy children (10 girls and 3 boys; age: $7.8 \pm 1.88$ years; height: $125.8 \pm 12.1 \mathrm{~cm}$; mass: $26.6 \pm 6.2 \mathrm{~kg}$; leg length discrepancy: $0.3 \pm 0.4 \mathrm{~cm}$ ) were also recruited with the same consent procedure and served as the control group matching with the DDH group without significant between-group differences in sex, age, height and body weight (BW). An a priori power analysis based on pilot results using G*POWER $3{ }^{16}$ determined that five subjects for each group would yield a power of 0.8 at a significance level of 0.05 . Thus, the number of subjects for each group was more than adequate for the main objectives of the current study. 
Table 1

Means (standard deviations) of the demographic characteristics of the juvenile patients treated for unilateral developmental dysplasia of the hip (DDH) during toddlerhood.

\begin{tabular}{|llll|}
\hline & Affected hip & Unaffected hip & $p$-Value \\
\hline Offset $(\mathrm{mm})$ & $21.5(8.2)$ & $22.3(5.4)$ & 0.501 \\
\hline Neck-shaft angle $\left(^{\circ}\right)$ & $144.5(11.1)$ & $143.7(9.5)$ & 0.781 \\
\hline Acetabular index $\left(^{\circ}\right)$ & $18.8(8.0)$ & $18.7(6.0)$ & 0.939 \\
\hline Center-edge angle $\left(^{\circ}\right)$ & $21.8(11.1)$ & $21.0(9.4)$ & 0.792 \\
\hline Acetabular depth ratio (mm/mm) & $0.24(0.05)$ & $0.26(0.04)$ & 0.196 \\
\hline Articulotrochanteric distance $(\mathrm{mm})$ & $19.8(5.2)$ & $18.9(5.5)$ & 0.470 \\
\hline c/b ratio (mm/mm) & $0.67(0.05)$ & $0.68(0.05)$ & 0.579 \\
\hline Alsberg angle $\left(^{\circ}\right)$ & $70.9(10.1)$ & $68.5(10.2)$ & 0.379 \\
\hline Age at gait experiment (years) & $6.7(2.3)$ & & - \\
\hline Age at surgery (years) & $2.3(1.5)$ & & - \\
\hline Body mass $(\mathrm{kg})$ & $24.3(8.1)$ & & - \\
\hline Body height (cm) & $117.6(16.2)$ & & - \\
\hline Body mass index & $17.4(3.5)$ & & - \\
\hline Leg length discrepancy (cm) & $0.5(0.27)$ & & - \\
\hline
\end{tabular}

In a hospital gait laboratory, each subject walked on a 10-m walkway at their preferred gait speed several times before data collection. To track the segmental motions of the pelvis-leg apparatus, light-weight retroreflective markers were attached to the anterior and posterior superior iliac spines, greater trochanters, mid-thighs, medial and lateral femoral epicondyles, fibular heads, tibial tuberosities, medial and lateral malleoli, navicular tuberosities, 5 th metatarsal bases, big toes and heels 17. Three-dimensional trajectories of the markers were measured using a 7-camera motion analysis system (MX T-40, Vicon Motion Systems Ltd., UK) and the ground reaction forces (GRF) were measured using three forceplates (AMTI, USA). At least six successful trials, each with a complete gait cycle for each limb, were obtained for each subject for subsequent analysis.

From the measured marker and forceplate data, the angular motions and resultant forces at the lower limb joints were calculated using inverse dynamics analysis with the pelvis-leg apparatus modelled as a 7-rigid-link system ${ }^{15 ;}{ }^{18-21}$. Before the analysis, the measured GRF and marker data were low-pass filtered with a 4th order Butterworth filter with cut-off frequencies of $25 \mathrm{~Hz}$ and $10 \mathrm{~Hz}$, respectively. Each body link was embedded with a local coordinate system with the positive $x-y$ - and z-axes directed anteriorly, superiorly and to the right, respectively 22 and a z-x-y Cardanic rotation sequence was used to calculate the joint angles ${ }^{23}$. The center of rotation of the hip was estimated using a functional method ${ }^{24}$, and those of the knee and ankle were defined as the mid-points between the lateral and medial femoral epicondyles and between the lateral and medial malleoli, respectively ${ }^{13}$. Body segmental inertial properties needed for joint force calculations were obtained using an optimization-based method ${ }^{25}$ and the effects of soft tissue artifacts were reduced using a global optimization method ${ }^{26}$. The axial components of the joint forces were calculated by projecting the resultant forces onto the long axis of the distal segment. Loading rates of the vertical GRF and the joint axial forces during initial contact and loading response phases, and their unloading rates during the pre-swing phase, were obtained as the maximum instantaneous slope of these force curves, calculated by finding the first derivatives of the spline curves fitted to the data using GCVSPL 19; 27 . All the force-related variables were normalized to body weight. Loading rate variables were averaged 
between left and right limbs for the healthy control group. Temporospatial gait parameters, namely stride length, stride time, step length, step width, cadence, and walking speed were also obtained.

Each of the calculated variables between affected and unaffected sides was compared using paired $t$-tests. Comparisons between Affected vs. Control and Unaffected vs. Control were performed using independent $t$-tests. The associations between each of the radiographic measurements, and the peak loading and unloading rates of the vertical GRFs, as well as the joint axial forces for both the affected and unaffected sides were obtained using Pearson's correlation analysis. A correlation coefficient of 0.7-0.9 indicated strong correlation, 0.4-0.6 moderate, and 0.1-0.3 weak correlation. All significance levels were set at $a=0.05$. All statistical analyses were performed using SPSS 20.0 (SPSS, IBM, Armonk, New York, USA).

\section{Results}

In the patient group, no significant differences were found in the morphological parameters between affected and unaffected sides (Table 1). Leg lengths of both sides were measured from scanography, and the mean leg length discrepancies were $0.5 \mathrm{~cm}$, which was not clinically significant (Table 1). The initial DLS of the affected limb was $1 \%$ longer than the unaffected $\operatorname{limb}(p=0.003)$. No significant between-side differences were found in the gait spatiotemporal parameters. No significant differences were found in the loading rates of the joint axial forces and vertical GRF between affected and unaffected sides (Table 2 and Fig. 2). 
Table 2

Means (standard deviations) of gait spatiotemporal parameters and the peak loading and unloading rates of the joint axial forces and vertical ground reaction forces (GRF).

\begin{tabular}{|c|c|c|c|c|c|c|}
\hline & \multicolumn{2}{|c|}{ DDH patients } & \multirow{2}{*}{$\begin{array}{l}\text { Healthy } \\
\text { Controls }\end{array}$} & \multirow{2}{*}{$\begin{array}{l}p \text {-value } \\
\text { Affected vs } \\
\text { Unaffected }\end{array}$} & \multirow{2}{*}{$\begin{array}{l}p \text {-value } \\
\text { Affected vs } \\
\text { Controls }\end{array}$} & \multirow{2}{*}{$\begin{array}{l}p \text {-value } \\
\text { Unaffected vs } \\
\text { Controls }\end{array}$} \\
\hline & $\begin{array}{l}\text { Affected } \\
\text { Limb }\end{array}$ & $\begin{array}{l}\text { Unaffected } \\
\text { Limb }\end{array}$ & & & & \\
\hline Walking speed (m/s) & $0.63(0.11)$ & & $0.67(0.08)$ & - & - & - \\
\hline Cadence (step/min) & $78.0(13.5)$ & & $81.9(8.5)$ & - & - & - \\
\hline Step width (cm) & $9.3(2.5)$ & & $9.4(3.1)$ & - & - & - \\
\hline Stride length & $\begin{array}{l}0.98 \\
(0.05)\end{array}$ & $0.97(0.07)$ & $0.99(0.09)$ & 0.700 & 0.714 & 0.664 \\
\hline Stride time & $1.1(0.2)$ & $1.1(0.1)$ & $0.90(0.1)$ & 0.409 & 0.000 & 0.000 \\
\hline Stance (\%) & $\begin{array}{l}60.1 \\
(1.7)\end{array}$ & $59.9(1.6)$ & $60.5(1.6)$ & 0.431 & 0.159 & 0.927 \\
\hline $\begin{array}{l}\text { Initial double-limb } \\
\text { support (\%) }\end{array}$ & $\begin{array}{l}11.4 \\
(2.0)\end{array}$ & $10.2(0.8)$ & $10.7(1.5)$ & 0.003 & 0.178 & 0.111 \\
\hline $\begin{array}{l}\text { Terminal double-limb } \\
\text { support (\%) }\end{array}$ & $9.9(0.8)$ & $9.8(1.5)$ & $10.5(1.5)$ & 0.539 & 0.073 & 0.306 \\
\hline \multicolumn{7}{|l|}{ Loading rate (BW/s) } \\
\hline \multicolumn{7}{|l|}{ Initial Contact } \\
\hline Hip, initial contact & $\begin{array}{l}47.2 \\
(17.41)\end{array}$ & $\begin{array}{l}45.1 \\
(17.27)\end{array}$ & $41.4(6.38)$ & 0.471 & 0.041 & 0.140 \\
\hline Knee, initial contact & $\begin{array}{l}51.2 \\
(18.16)\end{array}$ & $\begin{array}{l}48.8 \\
(18.32)\end{array}$ & $43.8(7.00)$ & 0.442 & 0.027 & .093 \\
\hline Ankle, initial contact & $\begin{array}{l}50.7 \\
(17.85)\end{array}$ & $\begin{array}{l}48.1 \\
(18.54)\end{array}$ & $43.0(6.52)$ & 0.454 & 0.025 & 0.098 \\
\hline \multicolumn{7}{|c|}{ Loading Response Phase } \\
\hline Hip & $\begin{array}{l}13.7 \\
(7.81)\end{array}$ & $13.9(4.63)$ & $14.0(3.23)$ & 0.904 & 0.926 & 0.890 \\
\hline Knee & $\begin{array}{l}14.5 \\
(7.51)\end{array}$ & $14.4(4.92)$ & $13.9(3.61)$ & 0.861 & 0.705 & 0.960 \\
\hline Ankle & $\begin{array}{l}12.3 \\
(6.57)\end{array}$ & $12.5(4.68)$ & $12.6(6.42)$ & 0.927 & 0.895 & 0.942 \\
\hline \multicolumn{7}{|l|}{ Unloading rate (BW/s) } \\
\hline Hip & $\begin{array}{l}17.6 \\
(5.35)\end{array}$ & $17.9(6.72)$ & $18.8(3.34)$ & 0.688 & 0.888 & 0.907 \\
\hline Knee & $\begin{array}{l}16.3 \\
(5.16)\end{array}$ & $16.0(5.78)$ & $16.6(2.52)$ & 0.534 & 0.802 & 0.836 \\
\hline Ankle & $\begin{array}{l}14.7 \\
(4.03)\end{array}$ & $14.4(4.49)$ & $14.7(2.14)$ & 0.663 & 0.789 & 0.701 \\
\hline
\end{tabular}




\begin{tabular}{|c|c|c|c|c|c|c|}
\hline & \multicolumn{2}{|c|}{ DDH patients } & \multirow{2}{*}{$\begin{array}{l}\text { Healthy } \\
\text { Controls }\end{array}$} & \multirow{2}{*}{$\begin{array}{l}\text { p-value } \\
\text { Affected vs } \\
\text { Unaffected }\end{array}$} & \multirow{2}{*}{$\begin{array}{l}\text { p-value } \\
\text { Affected vs } \\
\text { Controls }\end{array}$} & \multirow{2}{*}{$\begin{array}{l}\text { p-value } \\
\text { Unaffected vs } \\
\text { Controls }\end{array}$} \\
\hline & $\begin{array}{l}\text { Affected } \\
\text { Limb }\end{array}$ & $\begin{array}{l}\text { Unaffected } \\
\text { Limb }\end{array}$ & & & & \\
\hline Loading rate (BW/s) & $\begin{array}{l}54.6 \\
(23.88)\end{array}$ & $\begin{array}{l}54.1 \\
(19.98)\end{array}$ & $49.7(7.82)$ & 0.878 & 0.128 & 0.131 \\
\hline Loading rate (BW/s) & $\begin{array}{l}12.5 \\
(7.36)\end{array}$ & $\begin{array}{l}14.7 \\
(14.14)\end{array}$ & $13.0(6.92)$ & 0.844 & 0.661 & 0.446 \\
\hline Unloading rate (BW/s) & $\begin{array}{l}16.0 \\
(4.80)\end{array}$ & $15.9(4.69)$ & $18.2(2.78)$ & 0.677 & 0.339 & 0.295 \\
\hline
\end{tabular}

Compared to the healthy group, the stride time of the patient group was longer than that of the healthy control group ( $p<$ 0.05). No significant between-group differences were found in any other spatiotemporal parameters. Compared to the healthy controls, the patient group showed significantly greater peak loading rates of the joint axial forces in the affected $\operatorname{limb}(p=0.025$ to 0.041$)$ with a similar tendency in the unaffected limb during initial contact (Table 2).

For the vertical GRF during initial contact, in general, the peak loading and unloading rates were mainly correlated with the acetabular index of the unaffected side. Peak loading rates of both the affected and unaffected limbs were positively correlated with the acetabular index and $\mathrm{c} / \mathrm{b}$ ratio of the unaffected side (Table 3 ). The peak unloading rates of both limbs were also positively correlated with the acetabular index of the unaffected side (Table 3). During loading response, peak loading rates of the affected limbs were positively correlated with the acetabular index and c/b ratio of the unaffected side, but those during both initial contact and loading response phases were negatively correlated with the center-edge angle of the unaffected side (Table 3). 
Table 3

Correlations between loading and unloading rates of vertical ground reaction force and radiographic measurements of both affected $(A)$ and unaffected $(U)$ sides.

\begin{tabular}{|c|c|c|c|c|c|c|c|}
\hline & & \multicolumn{2}{|c|}{$\begin{array}{l}\text { Peak Loading Rate } \\
\text { (BW/s) }\end{array}$} & \multicolumn{2}{|c|}{$\begin{array}{l}\text { 2nd Peak Loading Rate } \\
\text { (BW/s) }\end{array}$} & \multicolumn{2}{|c|}{$\begin{array}{l}\text { Peak Unloading Rate } \\
\text { (BW/s) }\end{array}$} \\
\hline & & Affected & Unaffected & Affected & Unaffected & Affected & Unaffected \\
\hline \multirow[t]{2}{*}{ Offset (mm) } & A & -.015 & .046 & -.018 & .086 & 0.252 & 0.364 \\
\hline & $U$ & -.191 & -.159 & -.154 & -.046 & 0.12 & 0.209 \\
\hline \multirow[t]{2}{*}{ Neck-shaft angle $\left(^{\circ}\right)$} & $A$ & .122 & -.089 & .047 & -.187 & -0.298 & -0.345 \\
\hline & U & -.407 & -.055 & -.567 & .116 & -0.21 & -0.315 \\
\hline \multirow[t]{2}{*}{ Acetabular index $\left(^{\circ}\right)$} & A & .135 & .256 & .095 & .263 & 0.393 & 0.353 \\
\hline & U & .801 & .632 & .740 & .296 & 0.548 & 0.595 \\
\hline \multirow[t]{2}{*}{ Center-edge angle $\left(^{\circ}\right)$} & $A$ & -.407 & -.126 & -.274 & -.185 & -0.208 & -0.217 \\
\hline & U & -.709 & -.445 & -.769 & -.267 & -0.308 & -0.305 \\
\hline \multirow{2}{*}{$\begin{array}{l}\text { Acetabular depth ratio } \\
(\mathrm{mm} / \mathrm{mm})\end{array}$} & $A$ & -.141 & -.400 & -.299 & -.490 & -0.149 & -0.121 \\
\hline & $\mathrm{U}$ & -.375 & .010 & -.437 & -.039 & 0.03 & 0.051 \\
\hline \multirow{2}{*}{$\begin{array}{l}\text { Articulotrochanteric } \\
\text { distance }(\mathrm{mm})\end{array}$} & A & .062 & .094 & -.046 & .072 & 0.02 & -0.107 \\
\hline & $U$ & -.378 & .065 & -.558 & .134 & 0.004 & -0.099 \\
\hline \multirow[t]{2}{*}{$\mathrm{c} / \mathrm{b}$ ratio $(\mathrm{mm} / \mathrm{mm})$} & A & .304 & .141 & .018 & .045 & 0.247 & 0.255 \\
\hline & U & .594 & .535 & .498 & .432 & 0.436 & 0.418 \\
\hline \multirow[t]{2}{*}{ Alsberg angle $\left(^{\circ}\right)$} & A & .120 & .180 & .070 & .203 & -0.202 & -0.295 \\
\hline & U & -.255 & .136 & -.566 & .156 & -0.014 & -0.088 \\
\hline
\end{tabular}

For the joint axial forces during initial contact, the peak loading rates at the hip, knee and ankle on both sides were all positively correlated with the acetabular index of the unaffected side, while those on the affected side were correlated negatively with the center-edge angle of the unaffected side (Table 4). The peak axial force loading rate at the unaffected hip was also positively correlated with the Alsburg angle of the unaffected side, while those at the unaffected knee and ankle were positively correlated with the $\mathrm{c} / \mathrm{b}$ ratio of the unaffected side. The axial force unloading rates at the knee and ankle on the affected side were positively correlated with the acetabular index of the unaffected side, while that at the ankle on the unaffected side was positively correlated with the acetabular index of the unaffected side. During loading response phase, the peak loading rates at the knee and ankle on the affected limb were negatively correlated with the acetabular depth ratio of the affected limb (Table 4). 
Table 4

Correlations between loading and unloading rates of joint axial force and radiographic measurements of both affected (A) and unaffected $(U)$ sides. IC: initial contact; LR: loading response phase.

\begin{tabular}{|c|c|c|c|c|c|c|c|c|c|c|c|c|}
\hline & & & \multicolumn{2}{|c|}{$\begin{array}{l}\text { Acetabular } \\
\text { index }\left({ }^{\circ}\right)\end{array}$} & \multicolumn{2}{|c|}{$\begin{array}{l}\text { Center-edge } \\
\text { angle }\left({ }^{\circ}\right)\end{array}$} & \multicolumn{2}{|c|}{$\begin{array}{l}\text { Acetabular } \\
\text { depth ratio } \\
(\mathrm{mm} / \mathrm{mm})\end{array}$} & \multicolumn{2}{|c|}{$\begin{array}{l}\text { c/b ratio } \\
(\mathrm{mm} / \mathrm{mm})\end{array}$} & \multicolumn{2}{|c|}{$\begin{array}{l}\text { Alsberg angle } \\
\left(\left(^{\circ}\right)\right.\end{array}$} \\
\hline & & & $A$ & $U$ & $A$ & U & A & U & $A$ & U & $A$ & $U$ \\
\hline \multirow[t]{6}{*}{ Hip } & \multirow{2}{*}{$\begin{array}{l}\text { Loading, } \\
\text { IC }\end{array}$} & $A$ & 0.003 & 0.622 & -0.292 & -0.527 & -0.045 & -0.214 & 0.307 & 0.359 & -0.043 & -0.216 \\
\hline & & $U$ & 0.139 & 0.541 & -0.096 & -0.35 & -0.423 & -0.429 & 0.107 & 0.098 & 0.048 & 0.491 \\
\hline & \multirow{2}{*}{$\begin{array}{l}\text { Loading, } \\
\text { LR }\end{array}$} & A & 0.146 & 0.259 & -0.216 & -0.21 & -0.471 & -0.045 & 0.002 & 0.376 & 0.235 & 0.097 \\
\hline & & $U$ & 0.398 & 0.274 & -0.09 & 0.023 & -0.392 & 0.065 & 0.108 & 0.121 & -0.183 & 0.128 \\
\hline & \multirow[t]{2}{*}{ Unloading } & $A$ & 0.052 & 0.391 & -0.004 & -0.181 & -0.089 & -0.093 & 0.044 & 0.092 & 0.04 & 0.276 \\
\hline & & U & 0.094 & 0.362 & -0.04 & -0.199 & -0.274 & -0.072 & 0.033 & 0.301 & -0.035 & 0.101 \\
\hline \multirow[t]{6}{*}{ Knee } & \multirow{2}{*}{$\begin{array}{l}\text { Loading, } \\
\text { IC }\end{array}$} & $A$ & -0.03 & 0.613 & -0.262 & -0.552 & -0.043 & -0.234 & 0.278 & 0.354 & -0.001 & -0.204 \\
\hline & & U & 0.092 & 0.557 & -0.064 & -0.372 & -0.357 & -0.181 & 0.024 & 0.484 & 0.264 & 0.251 \\
\hline & \multirow{2}{*}{$\begin{array}{l}\text { Loading, } \\
\text { LR }\end{array}$} & $A$ & 0.095 & 0.275 & -0.17 & -0.246 & -0.526 & -0.095 & -0.038 & 0.423 & 0.311 & 0.123 \\
\hline & & U & 0.406 & 0.331 & -0.103 & -0.059 & -0.259 & -0.027 & 0.184 & 0.161 & -0.265 & 0.1 \\
\hline & \multirow[t]{2}{*}{ Unloading } & $A$ & -0.021 & 0.523 & -0.084 & -0.383 & -0.091 & -0.093 & 0.073 & -0.1 & 0.02 & 0.358 \\
\hline & & U & 0.002 & 0.457 & -0.045 & -0.341 & -0.191 & -0.202 & 0.019 & 0.322 & -0.026 & -0.012 \\
\hline \multirow[t]{6}{*}{ Ankle } & \multirow{2}{*}{$\begin{array}{l}\text { Loading, } \\
\text { IC }\end{array}$} & $A$ & 0.008 & 0.617 & -0.299 & -0.561 & -0.075 & -0.234 & 0.305 & 0.369 & 0.016 & -0.211 \\
\hline & & $U$ & 0.122 & 0.534 & -0.073 & -0.334 & -0.393 & -0.138 & 0.025 & 0.491 & 0.268 & 0.284 \\
\hline & \multirow{2}{*}{$\begin{array}{l}\text { Loading, } \\
\text { LR }\end{array}$} & A & 0.14 & 0.258 & -0.198 & -0.201 & -0.559 & -0.104 & -0.019 & 0.412 & 0.332 & 0.137 \\
\hline & & $\mathrm{U}$ & 0.326 & 0.303 & -0.061 & -0.094 & -0.312 & -0.181 & 0.318 & 0.243 & -0.038 & 0.252 \\
\hline & \multirow[t]{2}{*}{ Unloading } & A & -0.164 & 0.515 & -0.129 & -0.527 & -0.031 & -0.037 & 0.09 & -0.345 & -0.05 & 0.323 \\
\hline & & U & 0.016 & 0.502 & -0.12 & -0.387 & -0.249 & -0.192 & 0.05 & 0.394 & -0.016 & -0.035 \\
\hline
\end{tabular}

\section{Discussion}

The current study aimed to identify the loading and unloading rates of the GRF and joint axial forces in the lower limbs during gait, and their possible correlations with the bilateral hip morphology in juveniles who had been treated for DDH during toddlerhood. The patient group showed greater-than-normal peak loading rates of the joint axial forces, and the loading rates of the vertical GRF and joint axial forces on both the affected and unaffected sides were highly correlated to the acetabular index on the unaffected side. The peak unloading rates of the vertical GRF and the axial forces at the ankle and knee on the affected side and at the ankle on the unaffected side were also significantly correlated with the acetabular index on the unaffected side. These results suggest that apart from the regular follow-up of the morphological changes of the affected hip in current clinical practice, monitoring the loading rates and morphological changes of the unaffected hip after DDH reduction surgery is also important for early identification of any signs of insidious hip dysplasia and risk of premature degeneration of the cartilage. 
The juvenile subjects treated by Pemberton's osteotomy during infancy for DDH displayed increased loading rates of the vertical GRFs and joint axial forces in the affected limb, but showed a trend of increased loading rates in the unaffected limb only during initial contact and loading response of gait. Similar findings were found in adolescents who had been treated for DDH during infancy, except that the loading rates in the unaffected limb were significantly increased ${ }^{15}$. In another study, osteonecrosis (ON) which developed in the treated hip of adolescents with DDH was found to lead to significantly greater loading rates during loading response in both affected and unaffected hips when compared with the adolescents with $\mathrm{DDH}$ but without $\mathrm{ON}^{19}$. It has been suggested that the increased loading rates in the affected limb may be as a result of the compromised muscular control at the affected hip after surgery. Increased loading rates related to releasing of iliopsoas, rectus femoris and abductor longus by DDH surgery (muscles affected by surgery) increased the risk of premature hip OA. The greater than normal loading rate of the axial hip force in the unaffected limb during loading response was associated with the increased unloading rate of the vertical GRF in the affected limb, indicating that increased unloading rates would increase the loading rates in the contralateral limb. From the previous and current results, it appears that risk of premature $O A$ at the affected hip of the juvenile patients was already greater than the healthy peers, but the risk at the unaffected hip was still less than that at the affected hip, and may be managed so as to avoid further deterioration over time.

In the current study, the loading rates of the vertical GRFs and joint axial forces in both the affected and unaffected limb were highly correlated with the acetabular index and $c / b$ ratio of the unaffected hip. Acetabular index was the primary parameter correlated significantly with peak unloading rates on the sound side. A possible explanation of this finding may be related to the shorter lever arm of the abductors in the unaffected hip, exerting a lesser moment at the hip, leading to reduced stability at the hip during single-limb support, and thus poor control of heel strike of the affected limb resulting in an increased loading rate. Acetabular index may be the best predictor of late residual acetabular dysplasia after closed reduction in developmental dysplasia of the hip ${ }^{28}$. If more severe hip dysplasia were noted on the unaffected side, a greater loading rate but a lesser unloading rate would be noted on the affected side; this would be a result of the compensatory response of the sound side. The current results and previous studies on adolescents suggest that there is an increased risk of further deterioration such as insidious dysplasia of the unaffected hip over time during growth in the juvenile patients. This is because of an increase of the loading rates of the affected limb, which in turn further raises the risk of increased loading rates in the unaffected limb. Therefore, measures should be taken to manage the condition of the unaffected hip and to prevent further increases in the loading rates of the affected limb. Monitoring the loading and unloading rates of both limbs, and morphological changes of the unaffected hip in juveniles after DDH reduction surgery, is important for early identification of any signs of insidious hip dysplasia and risk of premature degeneration of the cartilage. In addition, the development of preventive strategies for the increased loading rates to reduce the risk of premature hip OA should be considered.

The current study suggests that monitoring the morphological changes over time is equally important for both hips during post-operative follow-up in patients treated for DDH. Generally, morphological measurements are performed mainly on the affected hip in follow-up visits to identify reduction quality, residual deformity or any subsequent osteonecrotic changes, and include parameters such as acetabular index, neck shaft angle, articulotrochanteric distance (ATD), c/b ratio and Alsberg angle. In a long-term follow-up of DDH after surgical reduction, 43\% of OA change was on the affected side ${ }^{29}$. However, the importance of follow-up of the morphology of the unaffected side was noted only in a limited number of studies. Terjesen reported $17 \%$ of normal side dysplasia following DDH surgery ${ }^{7}$. Insidious hip dysplasia was also noted in other studies in the literature ${ }^{30-32}$. The current findings of high correlation between the loading rates in both hips and the acetabular index and $\mathrm{c} / \mathrm{b}$ ratio of the unaffected hip suggest that monitoring the morphological changes in the unaffected hip is important for attempting to prevent the development of gait patterns with increased loading rates on both the unaffected and affected hips as found in previous adolescent studies. 
The current study was the first attempt to identify the correlational relationship between post-operative morphology of both hips and loading rates of the bilateral lower limb joints in juveniles treated for DDH during toddlerhood. Further study would be needed to investigate the effects of surgical age and methods on the subsequent long-term morphological and loading rate changes. The current study was limited to level walking. Further study on more challenging motor tasks such as stairclimbing and slope-walking may be needed to reveal other possible factors that may contribute to the development of gait patterns with increased loading rates at both hips.

\section{Conclusions}

The juvenile patients treated for DDH during toddlerhood showed greater-than-normal peak loading rates of the joint axial forces, and the loading rates of the GRF and joint axial forces on both the affected and unaffected sides were highly correlated with the acetabular index on the unaffected side. The peak unloading rates on the affected side were also significantly correlated with the acetabular index on the unaffected side. These results suggest that apart from regular follow-up of the affected hip, routine assessment of the morphological changes of the unaffected hip and/or increased loading rates after DDH reduction surgery is important for early identification of any signs of insidious hip dysplasia and risk of premature degeneration of the cartilage.

\section{Declarations}

\section{Conflict of Interest}

None of the authors have a conflict of interest.

\section{Acknowledgments}

The authors are grateful for the financial support from the Chang Gung Memorial Hospital (CMRPG1F0131) and the Ministry of Science and Technology of Taiwan (MOST 106-2221-E-182A-002), and for Mr. You-Lin Tsai's and Mr. Tzu-Ling Chang's assistance with data collection.

\section{References}

1. Feeley, I. H. et al. International variance in the treatment of developmental dysplasia of the hip. Journal of Children's Orthopaedics. 8, 381-386 (2014).

2. Barlow, T. G. Early diagnosis and treatment of congenital dislocation of the hip. The Journal of Bone and Joint Surgery British volume. 44-B, 292-301 (1962).

3. Danielsson, L. Late-diagnosed DDH: A prospective 11-year follow-up of 71 consecutive patients (75 hips). Acta Orthop. Scand. 71, 232-242 (2000).

4. Terjesen, T. \& Horn, J. 2020. Management of late-detected DDH in children under three years of age: 49 children with follow-up to skeletal maturity. Bone Jt Open; pp. 55-63.

5. Roposch, A. et al. Osteonecrosis Complicating Developmental Dysplasia of the Hip Compromises Subsequent Acetabular Remodeling. Clinical Orthopaedics and Related Research $® .471,2318-2326$ (2013).

6. Song, F. S. et al. The Incidence of Occult Dysplasia of the Contralateral Hip in Children With Unilateral Hip Dysplasia. Journal of Pediatric Orthopaedics. 28, 173-176 (2008).

7. Terjesen, T. Dysplasia of the contralateral hip in patients with unilateral late-detected congenital dislocation of the hip. The Bone \& Joint Journal. 96-B, 1161-1166 (2014). 
8. Kerin, A. J. et al. Propagation of surface fissures in articular cartilage in response to cyclic loading in vitro. Clin. Biomech. Elsevier Ltd. 18, 960-968 (2003).

9. Ewers, B. J. et al. Rate of blunt impact loading affects changes in retropatellar cartilage and underlying bone in the rabbit patella. Journal of Biomechanics. 35, 747-755 (2002).

10. Huang, S-C. et al. Effects of severity of degeneration on gait patterns in patients with medial knee osteoarthritis. Med. Eng. Phys. 30, 997-1003 (2008).

11. Liu, M-W. et al. Patients with type II diabetes mellitus display reduced toe-obstacle clearance with altered gait patterns during obstacle-crossing. Gait \& Posture. 31, 93-99 (2010).

12. Lu, T-W., Chen, H-L. \& Wang, T-M. Obstacle crossing in older adults with medial compartment knee osteoarthritis. Gait \& Posture. 26, 553-559 (2007).

13. RomanÒ, C. L. et al. 1996. Analysis of the Gait of Adults Who Had Residua of Congenital Dysplasia of the Hip*. JBJS 78.

14. Mündermann, A., Dyrby, C. O. \& Andriacchi, T. P. Secondary gait changes in patients with medial compartment knee osteoarthritis: Increased load at the ankle, knee, and hip during walking. Arthr. Rhuem. 52, 2835-2844 (2005).

15. Chang, C-F. et al. Adolescents after pemberton's osteotomy for developmental dysplasia of the hip displayed greater joint loading than healthy controls in affected and unaffected limbs during gait. Journal of Orthopaedic Research. 29, 1034-1041 (2011).

16. Faul, F. et al. G* Power 3: A flexible statistical power analysis program for the social, behavioral, and biomedical sciences. Behav. Res. Methods. 39, 175-191 (2007).

17. Cappozzo, A. et al. Position and orientation in space of bones during movement: anatomical frame definition and determination. Clin. Biomech. Elsevier Ltd. 10, 171-178 (1995).

18. Chang, C-F. et al. Residual gait deviations in adolescents treated during infancy for unilateral developmental dysplasia of the hip using Pemberton's osteotomy. Gait \& Posture. 35, 561-566 (2012).

19. Wang, T-M. et al. Loading rates during walking in adolescents with type II osteonecrosis secondary to pelvic osteotomy. Journal of Orthopaedic Research. 34, 2199-2206 (2016).

20. Lu, T-W. et al. Validation of a lower limb model with in vivo femoral forces telemetered from two subjects. Journal of Biomechanics. 31, 63-69 (1998).

21. Lu, T-W. et al. Influence of muscle activity on the forces in the femur: An in vivo study. Journal of Biomechanics. 30, 1101-1106 (1997).

22. Wu, G. \& Cavanagh, P. R. ISB recommendations for standardization in the reporting of kinematic data. Journal of Biomechanics. 28, 1257-1261 (1995).

23. Grood, E. S. \& Suntay, W. J. A joint coordinate system for the clinical description of three-dimensional motions: Application to the knee. J biomech eng. 105, 136-144 (1983).

24. Leardini, A. et al. Validation of a functional method for the estimation of hip joint centre location. Journal of Biomechanics. 32, 99-103 (1999).

25. Chen, S-C. et al. A method for estimating subject-specific body segment inertial parameters in human movement analysis. Gait \& Posture. 33, 695-700 (2011).

26. Lu, T-W. \& O'Connor, J. J. Bone position estimation from skin marker co-ordinates using globla optimisation with joint constraints. Journal of Biomechanics. 32, 129-134 (1999).

27. Woltring, H. J. A Fortran package for generalized cross-validatory spline smoothing and differentiation. Advances in Engineering Software. 8, 104-113 (1986).

28. Li, Y. et al. Acetabular index is the best predictor of late residual acetabular dysplasia after closed reduction in developmental dysplasia of the hip. Int. Orthop. 42, 631-640 (2018). 
29. Terjesen, T. 2018. Special symposium issue: Developmental dysplasia and dislocation of the hip. Journal of Children's Orthopaedics 12:294-295.

30. Jacobsen, S., Rømer, L. \& Søballe, K. 2006. The Other Hip in Unilateral Hip Dysplasia. Clinical Orthopaedics and Related Research 446.

31. Song, F. S. et al. 2008. The Incidence of Occult Dysplasia of the Contralateral Hip in Children With Unilateral Hip Dysplasia.Journal of Pediatric Orthopaedics28.

32. Jacobsen, S. Adult hip dysplasia and osteoarthritis: Studies in radiology and clinical epidemiology. Acta Orthop. 77, 237 (2006).

\section{Figures}

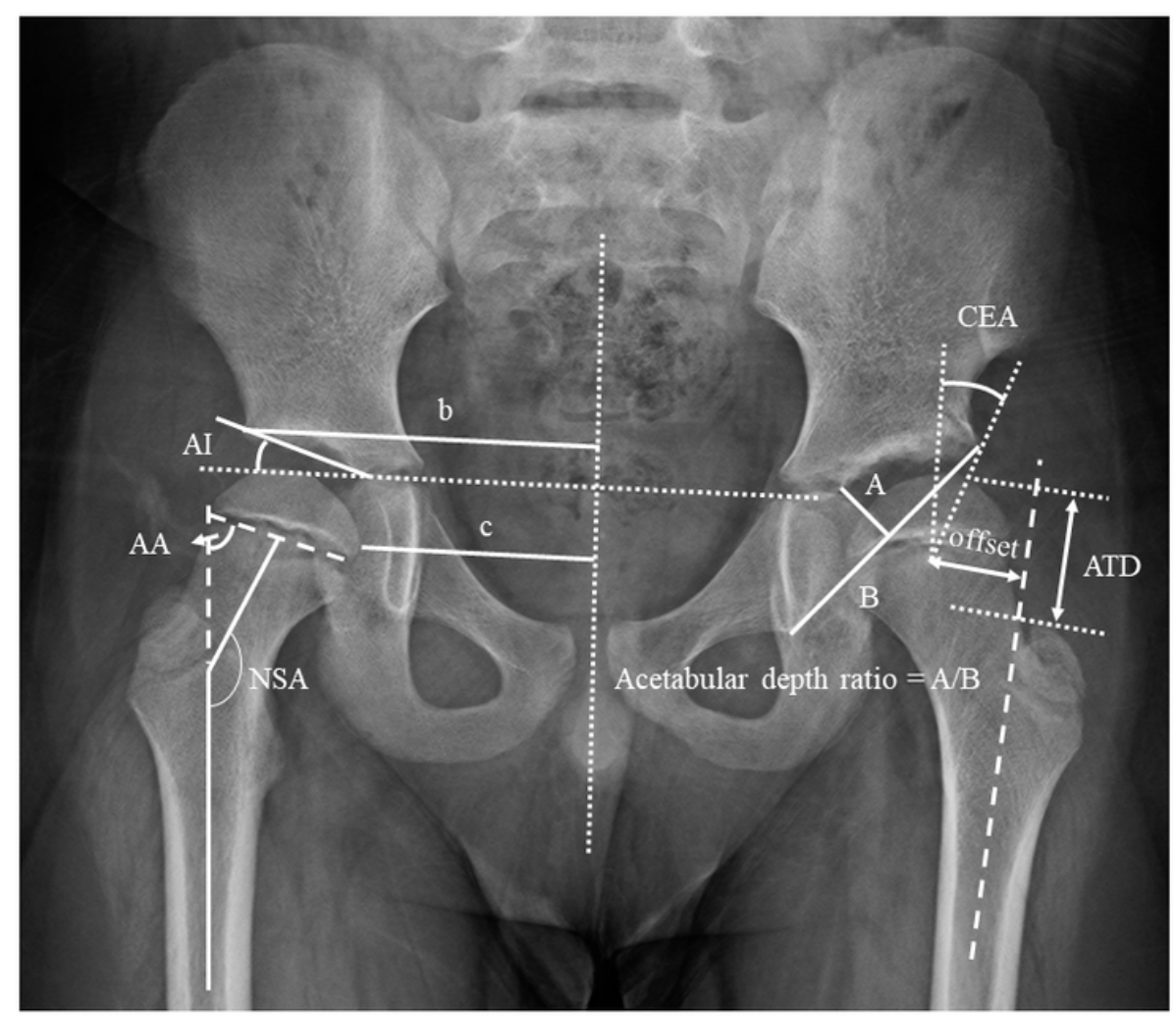

\section{Figure 1}

Definitions of the radiographical measurements of the morphology of the hip. NSA: neck-shaft angle; Al: acetabular index; CEA: center-edge angle; A/B: acetabular depth ratio; TAD: articulotrochanteric distance (TAD); c/b ratio; and AA: Alsberg angle. 


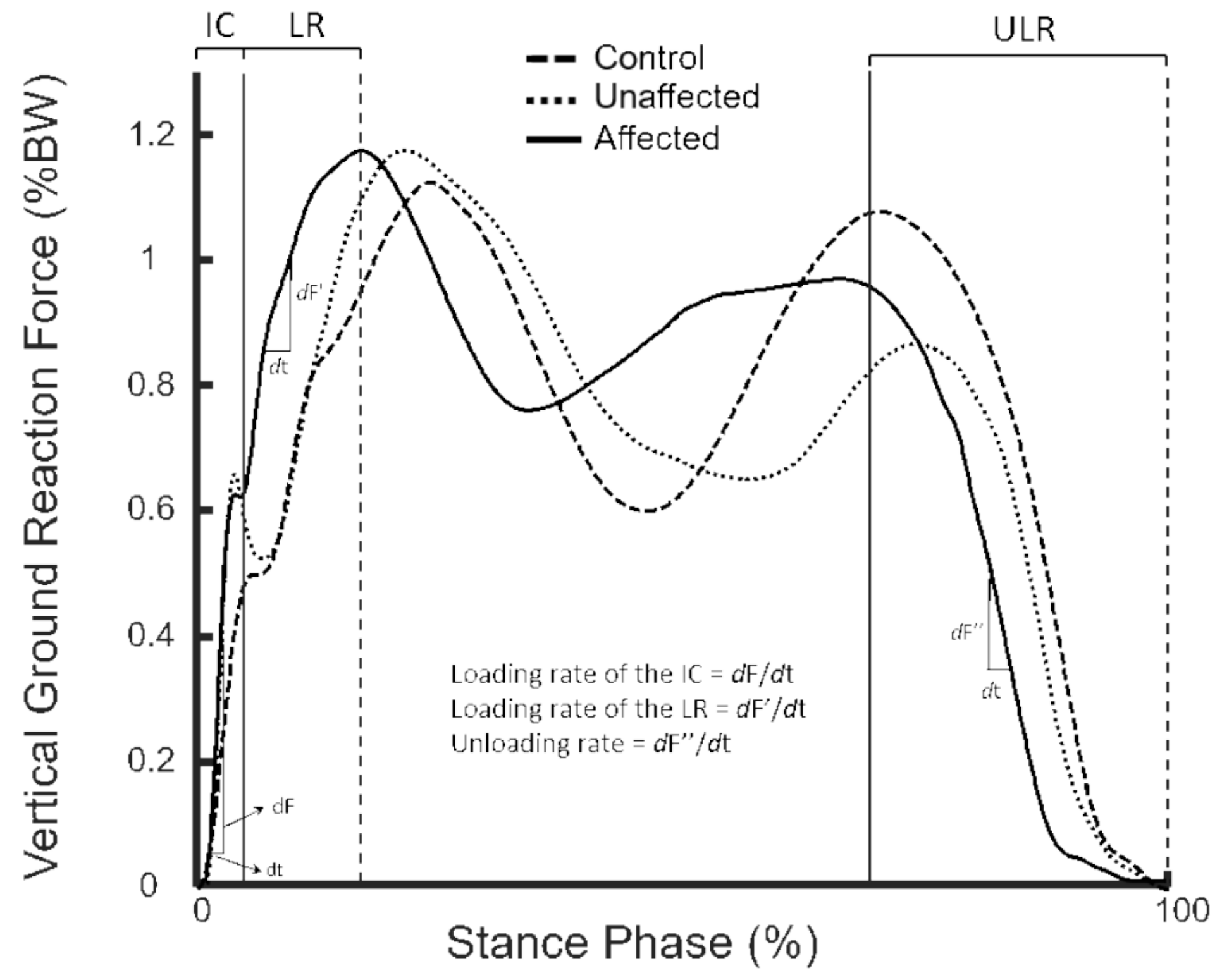

Figure 2

Curves of body-weight-normalized vertical ground reaction forces of the affected (solid line) and unaffected (dotted line) limbs of typical subjects in the DDH and Control group (dash line) during the stance phase of level walking. 